Check for updates

Cite this: RSC Adv., 2020, 10, 8453

Received 7th December 2019

Accepted 4th February 2020

DOI: $10.1039 / c 9 r a 10282 \mathrm{e}$

rsc.li/rsc-advances

\section{Investigation into the electrochemical behaviour of silver in alkaline solution and the influence of Au- decoration using operando Raman spectroscopy}

\begin{abstract}
Haowei Luo, ${ }^{\mathrm{X}} \mathrm{Xu} \mathrm{Jib}$ and Shuang Cheng (iD *a
To explore the basic chemistry in the electrochemical environment, the electrochemical behavior of Ag and the influence of Au decoration is investigated with cyclic voltammetry (CV), galvanostatic charge-discharge (GCD) and operando Raman measurements in a $1 \mathrm{M} \mathrm{KOH}$ solution. During the anodic CV sweep, Ag is oxidized to $\mathrm{Ag}_{2} \mathrm{O}$ in the first step through a one-electron process, and then, $\mathrm{AgO}$ in the second step through another one-electron process. Meanwhile, some $\mathrm{AgO}$ is formed at a relatively low potential under the irradiation of visible lights (photoelectrochemical oxidation). In the GCD mode, it is found that apart from the two one-electron processes, part of the $\mathrm{Ag}$ is oxidized to $\mathrm{AgO}$ directly through a twoelectron process in the second oxidation step, implying slightly different activities of these reactions in the CV and GCD mode. During cathodic CV sweep and galvanostatic discharge, opposite reactions take place respectively. The coulombic efficiency is calculated to be only $\sim 82 \%$ from the CV cycle at $5 \mathrm{mV}$ $\mathrm{s}^{-1}$ due to the formation of silver hydroxyl species (oxidation state) in a low potential range. For the $\mathrm{Au}$ decorated Ag, Raman signals from these species disappeared and the coulombic efficiency is enhanced to $95 \%$, indicating an obvious improvement in reversibility.
\end{abstract}

\section{Introduction}

With the increasing demand for energy in the human society, the development of renewable energy has been promoted in the past few decades, with a variety of energy storage devices including supercapacitors and rechargeable batteries. ${ }^{1-4}$ Supercapacitors have been applied to various fields such as sustainable energy collection (e.g. wind and tidal energy) and electric automobiles because of their high power density., ${ }^{5,6}$ However, their widespread use has been limited by low energy density. Batteries, especially lithium-ion batteries, are famous for their high energy density, while their rate performance and safety are always unsatisfied. The construction of aqueousbased batteries is one of the effective approaches to balance the power and energy density as well as safety. The exploration of suitable electrodes that can be used in aqueous systems is critical, including anodes and cathodes.

$\mathrm{Ag}$, famous for its use in $\mathrm{SERS}^{7}$ due to the existence of surface plasmon resonance (SPR), ${ }^{8-10}$ has been well considered as cathodes for alkaline solutions in recent years, especially in zincsilver (Zn-Ag) batteries, ${ }^{11,12}$ due to its high capacity and high operational potential. $\mathrm{Ag}-\mathrm{Zn}$ battery is one of the promising

${ }^{a}$ Guang Zhou Key Laboratory for Surface Chemistry of Energy Materials, School of Environment and Energy, South China University of Technology, Guangzhou 510006, P. R. China. E-mail: escheng@scut.edu.cn

${ }^{b}$ College of Automation, Zhongkai University of Agriculture and Engineering, Guangzhou, 510225, China aqueous batteries that possesses high energy density owing to the high capacities for both electrodes and a considerable output voltage. However, when used as a cathode in a battery, there were problems, including the low coulombic efficiency caused by incomplete reversible reactions and the low power density owing to the use of un-conductive polymer binders and the high resistance of the middle product $\mathrm{Ag}_{2} \mathrm{O}$, which have greatly hindered its further development. To address these issues, binder-free electrodes have been explored..$^{13}$ Besides, the composition of nanostructured noble metals (such as gold and platinum) has also been considered as a promising approach because of their high electronic conductivity and high inertia. ${ }^{14}$ However, to figure out a possible solution to the problems aroused by the reaction of Ag, its electrochemical behavior needs to be thoroughly investigated.

Commonly, the faradic reactions of silver involve two redox reaction steps at equilibrium potential corresponding to a oneelectron-transfer process for each step as follows: ${ }^{12}$

$$
\begin{gathered}
\mathrm{Ag}+\mathrm{OH}^{-} \leftrightarrow \frac{1}{2} \mathrm{Ag}_{2} \mathrm{O}+\frac{1}{2} \mathrm{H}_{2} \mathrm{O}+\mathrm{e}^{-} \quad E=0.247 \mathrm{~V}(v s . \mathrm{Hg} / \mathrm{HgO}) \\
\frac{1}{2} \mathrm{Ag}_{2} \mathrm{O}+\mathrm{OH}^{-} \leftrightarrow \mathrm{AgO}+\frac{1}{2} \mathrm{H}_{2} \mathrm{O}+\mathrm{e}^{-} E=0.509 \mathrm{~V}(v s . \mathrm{Hg} / \mathrm{HgO})
\end{gathered}
$$

Eqn (1) stands for the first oxidation step from $\mathrm{Ag}$ to $\mathrm{Ag}_{2} \mathrm{O}$, at operation potential $\sim 0.35 \mathrm{~V} v s$. $\mathrm{Hg} / \mathrm{HgO}$ during the anodic 
sweep, which is a diffusion-limited process. The later equation corresponds to the second oxidation step at operation potential $\sim 0.7 \mathrm{~V} v s . \mathrm{Hg} / \mathrm{HgO}$ where $\mathrm{Ag}(\mathrm{I})$ is further oxidized at a higher valence of $\mathrm{Ag}(\mathrm{II})$, which is a nucleation and growth process. The theoretical capacity of $\mathrm{Ag}$ is up to $893 \mathrm{C} \mathrm{g}^{-1}$ for a one-electrontransfer process, which should be doubled for the two reaction steps. However, the practical capacity is often far below this value when $\mathrm{Ag}$ is used as the cathode in a battery. ${ }^{\mathbf{1 5 , 1 6}}$

Although the electrochemical behavior of silver in alkaline solution has been discussed in previous reports, ${ }^{17,18}$ these studies are not systematic and only the two reaction steps were discussed with cyclic voltammetry (CV) scans. Most importantly, no solutions have ever been proposed towards the irreversible reactions as well as the low coulombic efficiency. Herein, the behavior of $\mathrm{Ag}$ in $1 \mathrm{M} \mathrm{KOH}$ is fully investigated using CV, galvanostatic charge-discharge (GCD) and operando Raman analysis during the CV cycling. It is found that, except for the traditional reaction mechanism discussed above, there is a two-electron process during the second reaction step in the GCD mode. Furthermore, a possible approach is proposed to enhance the reversibility of the faradic reactions.

\section{Results and discussion}

\section{Electrochemical performance analysis}

Electrochemical tests were conducted in a three-electrode system using a $1 \mathrm{M} \mathrm{KOH}$ aqueous solution as the electrolyte and $\mathrm{Hg} / \mathrm{HgO}$ as the reference electrode, as shown in Fig. 1. Fig. 1a exhibits the general $\mathrm{CV}$ curve at $5 \mathrm{mV} \mathrm{s}^{-1}$. Two obvious oxidation peaks named as $\mathrm{A} 1$ with a front peak in the range of $0.25-0.5 \mathrm{~V}$ and $\mathrm{A} 2$ centred at $\sim 0.65 \mathrm{~V}$ can be observed at the anodic sweep curve. The A1 peak concerns the oxidation of Ag to
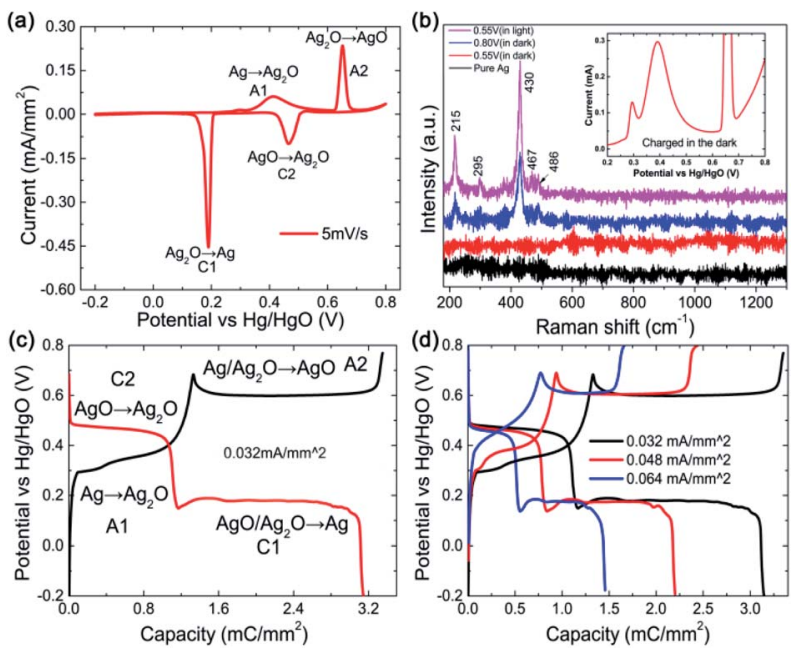

Fig. 1 (a) Typical CV curve at $5 \mathrm{mV} \mathrm{s}^{-1}$. (b) Ex situ Raman spectra of the Ag wire collected at different potentials during the first anodic sweep running in dark or in natural light: black curve, pristine Ag; red curve, stopped at $0.55 \mathrm{~V}$ and blue curve, stopped at $0.8 \mathrm{~V}$ running in dark; magenta curve, stopped at $0.55 \mathrm{~V}$ running in natural light; inset, enlarged part $C V$ curve charging from $0.2 \mathrm{~V}$ to $0.8 \mathrm{~V}$. GCD curves (c) at a current density of $0.032 \mathrm{~mA} \mathrm{~mm} \mathrm{~mm}^{-2}$ and (d) at various current densities.
$\mathrm{Ag}_{2} \mathrm{O}$ and the $\mathrm{A} 2$ peak should correspond to the further oxidation of $\mathrm{Ag}_{2} \mathrm{O}$ to $\mathrm{AgO}$. In fact, the A1 peak together with its front peak is composed of 3 peaks. ${ }^{18}$ The front peak is assigned to the oxidation of $\mathrm{Ag}$ to $\mathrm{Ag}_{2} \mathrm{O}$ in the superficial layer and the latter two (looks like one peak in this work) are in the layers below. ${ }^{\mathbf{1 9 2 0}}$

To confirm the reaction step mentioned above, ex situ Raman spectroscopy measurements were performed on the samples in different situations, as shown in Fig. 1b. No Raman bands arising from $\mathrm{Ag}_{2} \mathrm{O}$ can be observed in any of the spectra due to the high light sensitivity of $\mathrm{Ag}_{2} \mathrm{O} .{ }^{21}$ In addition, there are no Raman bands for the electrode after the anodic sweep to $0.55 \mathrm{~V}$ (ending of the A1 peak) in dark (see the red curve in Fig. 1b), indicating that the A1 peak corresponds to the formation of $\mathrm{Ag}_{2} \mathrm{O}$. Five bands at 215, 295, 430, 467 and $486 \mathrm{~cm}^{-1}$ that can be assigned to AgO emerge after the anodic sweep to $0.8 \mathrm{~V}$ (ending of the A2 peak, see the blue curve), indicating that the $\mathrm{A} 2$ peak corresponds to the formation of AgO. However, for the electrode tested in natural light, obvious Raman bands arising from AgO after the anodic sweep to $0.55 \mathrm{~V}$ can be observed (see the magenta curve), which is attributed to the photoelectrochemical oxidation of $\mathrm{Ag}$ to $\mathrm{AgO}$ in a low potential range. ${ }^{22}$ From the partially enlarged CV curve collected in the dark (inset of Fig. 1b), it can be seen that except for the two oxidation peaks of A1 and A2, the front peak of A1 is also observable, which means that there is no difference for the CV curves collected in darkness and in natural light, implying that only a little amount of photoelectrochemical reaction induced $\mathrm{AgO}$ is formed.

Reversible reactions occur during the cathodic sweep and two reduction peaks (named $\mathrm{C} 2$ and $\mathrm{C} 1$ ) are observed, which should correspond to the reduction of $\mathrm{AgO}$ to $\mathrm{Ag}_{2} \mathrm{O}$ and $\mathrm{Ag}_{2} \mathrm{O}$ to $\mathrm{Ag}$, respectively. The coulombic charge passed by for each reaction can be calculated from the integration of the corresponding CV peak area, as presented in Table 1. It can be seen that the charges passed though peaks A1 and $\mathrm{C} 1$ are much larger than those of peaks $\mathrm{A} 2$ and $\mathrm{C} 2$, indicating that only a part of $\mathrm{Ag}_{2} \mathrm{O}$ is oxidized to $\mathrm{AgO}$ during the second oxidation step. The total charge transfer during reduction is less than that during oxidation and the coulombic efficiency is about $82 \%$, which means that the reactions are not fully reversible.

To further investigate the electrochemical behavior of $\mathrm{Ag}$, GCD measurements were performed at $0.032 \mathrm{~mA} \mathrm{~mm}{ }^{-2}$, as shown in Fig. 1c. Two obvious plateaus at $\sim 0.3 \mathrm{~V}$ and $0.6 \mathrm{~V}$ corresponding to the two-step oxidation process can be seen in the charge curve (dark line) and the reverse process can be observed in the discharge curve, which is consistent with the CV result. Similarly, two unusual phenomena are worth

Table 1 Digital values calculated from the GCD and CV results in Fig. 1 and 3

\begin{tabular}{llllll}
\hline Anodic/cathodic peaks & & A1 & A2 & C2 & C1 \\
\hline CV capacity $\left(\mathrm{mC} \mathrm{mm}^{-2}\right)$ & Pristine Ag & 2.06 & 1.28 & 0.8 & 1.95 \\
& Treated Ag & 6.45 & 5.17 & 3.79 & 7.19 \\
GCD capacity $\left(\mathrm{mC} \mathrm{mm}^{-2}\right)$ & Pristine Ag & 0.35 & 2.40 & 0.32 & 2.17 \\
& Treated Ag & 2.16 & 5.17 & 1.75 & 5.46
\end{tabular}


mentioning. One is the super long plateau for the second charge step, much longer than that for the first step, indicating much more charge-transfer during the second step, which is quite different from the $\mathrm{CV}$ result. The other one is a sudden potential drop in the second plateau during charge (A2). As is well known, the charge passed during the second oxidation step $\left(\mathrm{Ag}_{2} \mathrm{O}\right.$ to $\mathrm{AgO})$ should be less than that during the first step. One of the reasonable explanations is the direct oxidation of $\mathrm{Ag}$ to $\mathrm{AgO}$ through a two-electron process in the second step, which is not obvious in a potential continuous rising process of $\mathrm{CV}$, implying a slightly different reaction process in the GCD mode and CV mode. The sudden potential drop at the beginning of the A2 and the sudden increase at the beginning of the $\mathrm{C} 1$ plateaus should be related to the high resistance of $\mathrm{Ag}_{2} \mathrm{O}$ (Table 2). When the $\mathrm{Ag}_{2} \mathrm{O}$ formed at the first oxidation step covered the surface of $\mathrm{Ag}$, the charge potential should be high, while it would be reduced along with the formation of more conductive AgO. Moreover, the GCD curves at various currents display similar profiles (Fig. 1d), indicating that the reaction process is decided mainly by the current mode, constant or not, but not by the magnitude.

To confirm the direct reaction of $\mathrm{Ag}$ to $\mathrm{AgO}$, ex situ X-ray diffraction (XRD) patterns and Raman spectra were collected at different points (I to V) during the GCD, as shown in Fig. 2b-d, because $\mathrm{Ag}_{2} \mathrm{O}$ is detectable with XRD while $\mathrm{AgO}$ is sensitive to Raman spectroscopy. $\mathrm{Ag}_{2} \mathrm{O}$, but not $\mathrm{AgO}$, is detected at point I, indicating that only $\mathrm{Ag}_{2} \mathrm{O}$ is formed during the first oxidation step. The clear Raman signal that can be assigned to AgO emerged at points II, III and IV, implying that $\mathrm{AgO}$ is formed in

Table 2 Resistivity and density of $\mathrm{Ag}, \mathrm{Ag}_{2} \mathrm{O}$ and $\mathrm{AgO}$

\begin{tabular}{llll}
\hline Substance & $\mathrm{Ag}$ & $\mathrm{Ag}_{2} \mathrm{O}$ & $\mathrm{AgO}$ \\
\hline Resistivity $(\Omega \mathrm{cm})$ & $1.59 \times 10^{-6}$ & $10^{8}$ & $10-15$ \\
Density $\left(\mathrm{g} \mathrm{cm}^{-3}\right)$ & 10.9 & 7.15 & 7.44
\end{tabular}
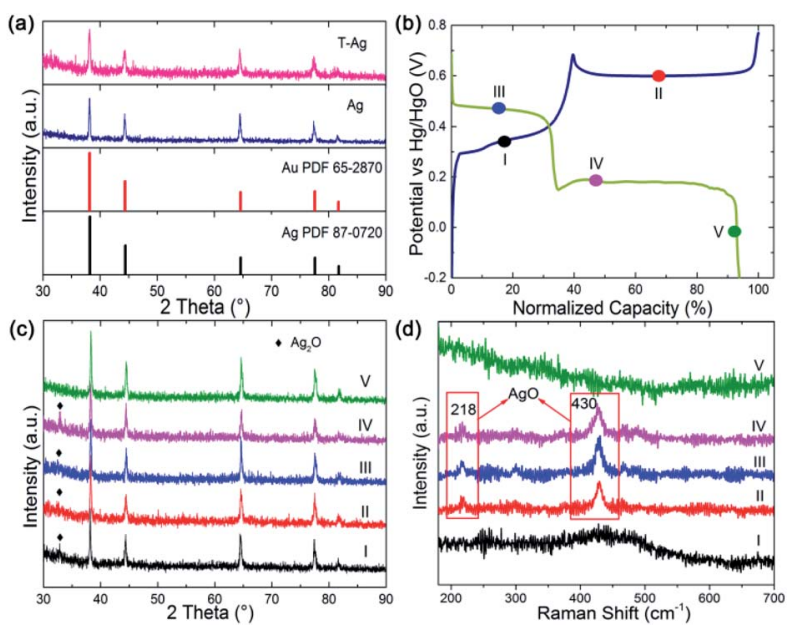

Fig. 2 (a) XRD of Ag and Au modified Ag wires. (b) GCD curve of Ag for ex situ XRD and Raman measurement. (c) XRD pattern and (d) Raman spectrum collected at point I to $V$ in (b). the second oxidation step and it is not fully reduced after the first reduction step. AgO was left at the beginning of the second reduction step, while it disappeared at the end of this step and only Ag could be detected (reflected by the Raman and XRD result for point V). From these results, it can be clearly seen that $\mathrm{AgO}$ is directly reduced to $\mathrm{Ag}$ through a two-electron process during the second reduction step. The direct reaction of AgO to $\mathrm{Ag}$ or $\mathrm{Ag}$ to $\mathrm{AgO}$ can avoid the formation of high resistance $\mathrm{Ag}_{2} \mathrm{O}$, which offers a promising strategy to resolve the rate issue of Agbased chemical cells.

After being treated (modified with $\mathrm{Au}$ and part of the $\mathrm{Ag}$ on the surface is replaced by Au atoms, the sample is named as T$\mathrm{Ag}$ ), the $\mathrm{CV}$ and GCD profiles have no obvious changes compared with those of the pristine Ag sample (Fig. 3); the amount of $\mathrm{Au}$ is undetectable from XRD patterns (Fig. 2a). Meanwhile, it can be clearly seen that T-Ag exhibits much larger redox peaks than pristine $\mathrm{Ag}$ with the same sweep rate and geometric area (see Fig. 3a), which should result from the roughened surface and enhanced conductivity after the modification of $\mathrm{Au}$. There are no reaction peaks related to $\mathrm{Au}$, indicating that $\mathrm{Au}$ is stable during the electrochemical test.

From the digital values on the charge passed by, as shown in Table 1 , it can be calculated that the coulombic efficiency is enhanced to $95 \%$ from $82 \%$ for the CV scan mode, indicating an improvement in the redox reactions' reversibility. In detail, the ratio of the $\mathrm{Ag}_{2} \mathrm{O}$ that is oxidized to $\mathrm{AgO}$ in the second reaction step as well as the ratio of the reverse reaction where AgO is reduced to $\mathrm{Ag}_{2} \mathrm{O}$ in the first discharge step is largely enhanced. For the GCD mode, the coulombic efficiency is also improved to $98 \%$ from $91 \%$ after modification.

\section{Morphology characterization}

Scanning electron microscopy (SEM) was used to explore the morphology change of the pristine Ag sample along with the CV cycling under natural light (Fig. 4). Before testing with an open circuit potential (OCP), the surface of the sample is not smooth with some particles distributed on it, as presented in Fig. 4a. Along with the anodic sweep, after the first step corresponding to the oxidation of $\mathrm{Ag}$ to $\mathrm{Ag}_{2} \mathrm{O}$ (stopped at $0.6 \mathrm{~V}$ ), $\mathrm{Ag}_{2} \mathrm{O}$ particles are formed with different sizes in the range of tens to hundreds of nanometers (Fig. 4b), which further confirms the prior statement that the oxidation of $\mathrm{Ag}$ to $\mathrm{Ag}_{2} \mathrm{O}$ is controlled by a diffusion process. ${ }^{18}$ Besides, there are few very small
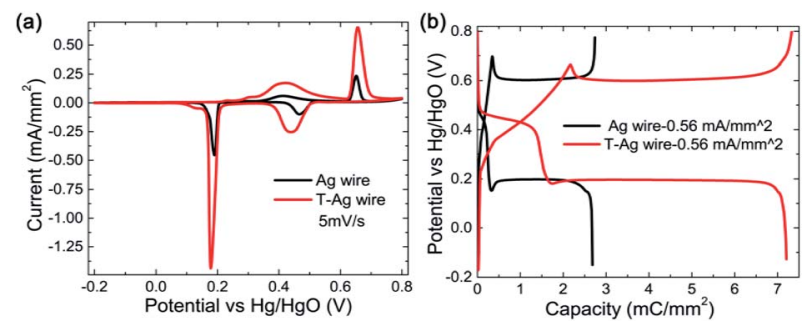

Fig. 3 (a) CV and (b) GCD curves of pristine Ag and the T-Ag and at a same sweep rate and a same charge/discharge current density, respectively. 

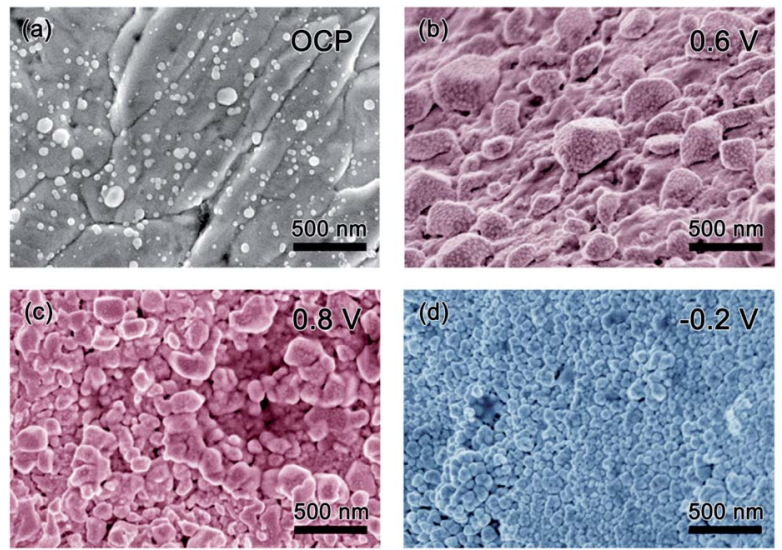

Fig. 4 SEM images of the pristine Ag sample before CV cycling (a) and along CV cycling when the sweep potential stopped at different position: anodic sweep (b) $0.6 \mathrm{~V}$ and (c) $0.8 \mathrm{~V}$, cathodic sweep (d) $-0.2 \mathrm{~V}$

nanoparticles on the surface of the large $\mathrm{Ag}_{2} \mathrm{O}$ particles, which should be the photoelectrochemical product of $\mathrm{AgO}$ because it is reported that its formation is controlled by nucleation and growth processes and hence its size should be relatively uniform. Seen from the image collected after the second oxidation step (stopped at $0.8 \mathrm{~V}$ ), AgO particles of relative uniform size are formed, as presented in Fig. 4c. When the potential is stopped at $-0.2 \mathrm{~V}$ in the cathodic sweep during the reduction process, $\mathrm{Ag}$ nanoparticles with a uniform size of several tens of $\mathrm{nm}$ are formed (Fig. 4d). The results coincide with the prior report, ${ }^{18}$ which defends that the oxidation of $\mathrm{Ag}_{2} \mathrm{O}$ to $\mathrm{AgO}$ and the reduction of $\mathrm{Ag}_{2} \mathrm{O}$ to $\mathrm{Ag}$ are controlled by nucleation and growth processes. Meanwhile, it can be seen that CV cycling is a good way to prepare Ag nanoparticles for SERS research. ${ }^{23}$

To explore the effect of Au decoration, the surface change of the T-Ag along cycling was also recorded in Fig. 5. After decoration at OCP, most of the Ag surface is covered by particles, as shown in Fig. 5a. From the energy dispersion spectra (EDS, Fig. $5 \mathrm{~b}$ ) of three different positions pointed in Fig. 5a, the particles formed on the surface are mainly Au while the bare surface remains Ag. During the anodic CV sweep under natural light, larger particles are formed among the Au particles at $0.6 \mathrm{~V}$ (Fig. 5c), which should be the high resistant $\mathrm{Ag}_{2} \mathrm{O}$. Because of the existence of $\mathrm{Au}$ particles, the continuous distribution of $\mathrm{Ag}_{2} \mathrm{O}$ is broken to some extent. As the potential is increased to $0.8 \mathrm{~V}$, the inhomogeneity of the particles increases (Fig. 5d). During the cathodic sweep, when the potential is reduced to $-0.2 \mathrm{~V}, \mathrm{Ag}$ nanoparticles with a smooth surface and the smaller size are formed (Fig. 5e). Although it is difficult to distinguish $\mathrm{Au}$ particles from $\mathrm{Ag}$ or $\mathrm{AgO}_{x}$ ones, it can be speculated that $\mathrm{Au}$ particles remain among these species during the cycling and benefit from the fast electronic transport of the electrode.

\section{In situ Raman spectroscopy analysis}

To confirm the oxidation steps discussed above, operando Raman spectroscopy measurement (Fig. 6) is employed to monitor the change of the surface species during the charge/ discharge process. One spectrum is recorded every 160 seconds and a total of 21 spectra can be obtained in one CV cycle in a potential range of $-0.2 \mathrm{~V}$ to $0.8 \mathrm{~V}$ at a sweep rate of $0.625 \mathrm{mV} \mathrm{s}^{-1}$. The corresponding Raman spectra obtained are presented in Fig. 6b. Almost no Raman bands can be observed between $-0.2 \mathrm{~V}$ and $0.2 \mathrm{~V}$ during the anodic sweep, suggesting that Raman active oxides are not formed. Then, five bands (named as bands 1 to 5 ) that can be indexed to $\mathrm{AgO}^{\mathbf{2 4}}$ are
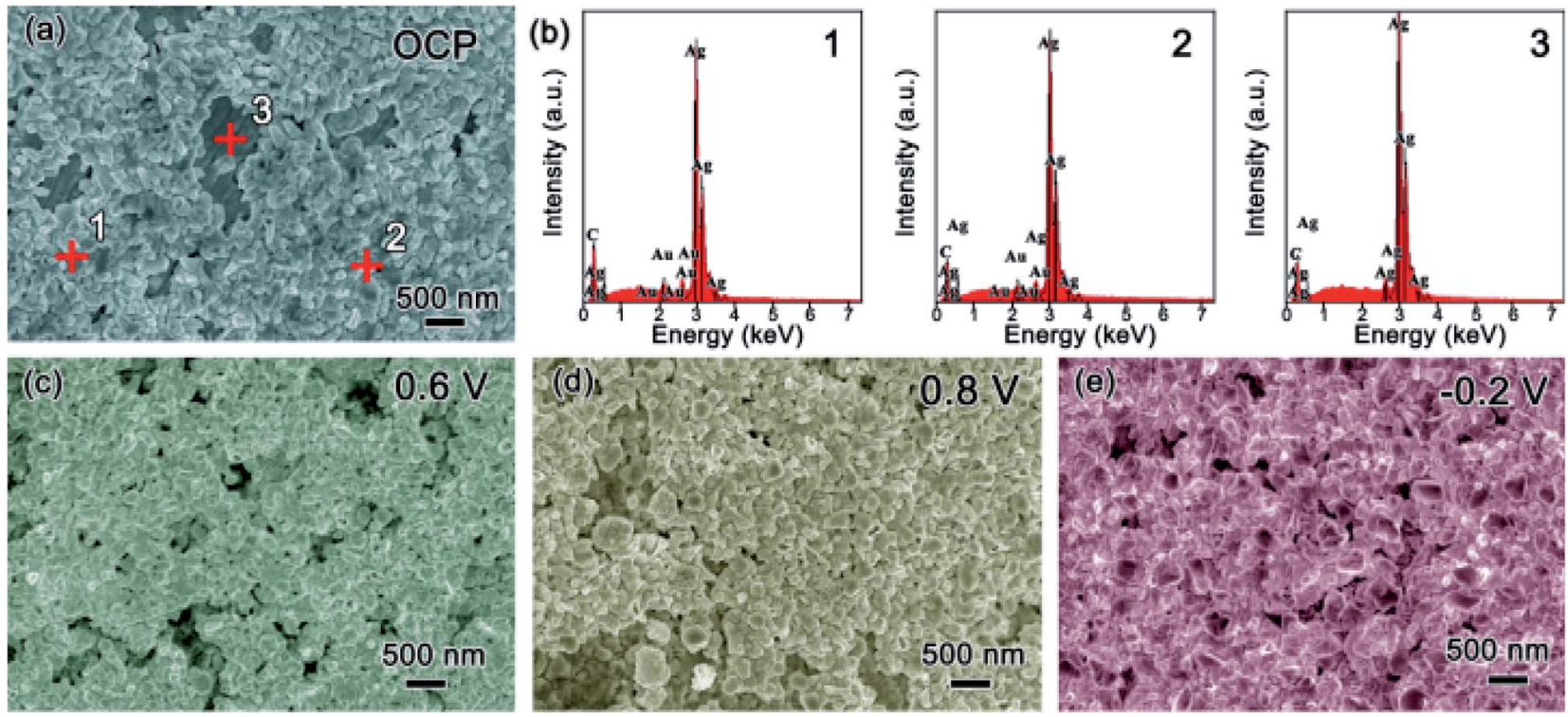

Fig. 5 Characterization to the T-Ag sample: (a) SEM image at OCP and (b) EDS of different positions pointed in (a) ( 1 and 2 for decorated area and 3 for bare area); SEM images along CV and stopped at different potential (c) $0.6 \mathrm{~V}$ and (d) $0.8 \mathrm{~V}$ during the anodic sweep and (e) $-0.2 \mathrm{~V}$ during the cathodic sweep. 

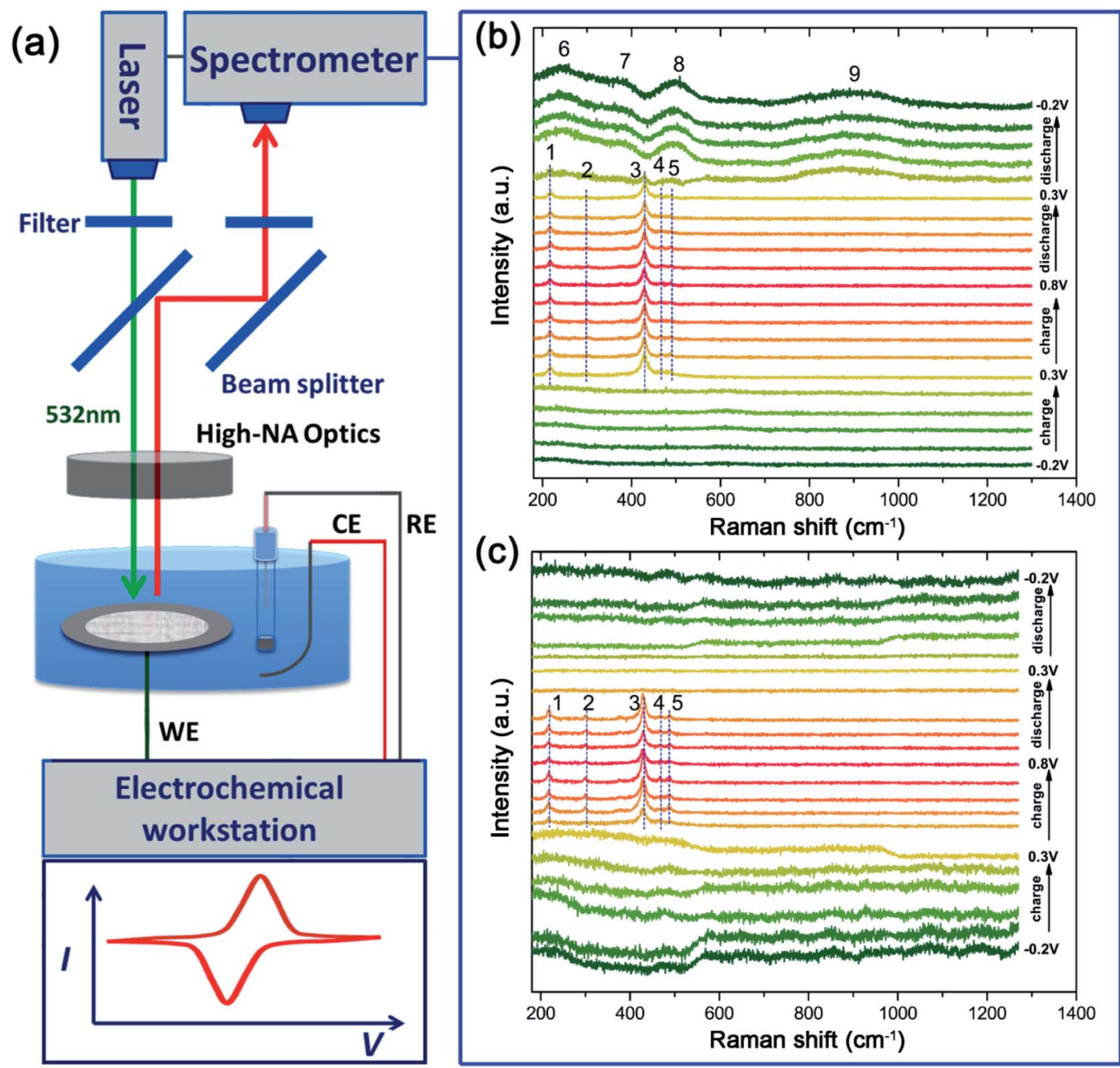

Fig. 6 (a) Schematic of the equipment for operando Raman spectroscopy and the operando Raman spectra of the pristine silver electrode (b) and the T-Ag electrode (c) collected every 160 seconds during a CV cycle at a sweep rate of $0.625 \mathrm{mV} \mathrm{s}^{-1}$.

observed at $0.3 \mathrm{~V}$, which are maintained in the following anodic sweep till the potential rises to $0.8 \mathrm{~V}$. As discussed above, AgO should be formed at a higher potential of $\sim 0.7 \mathrm{~V}$. The $\mathrm{AgO}$ signal observed at $0.3 \mathrm{~V}$ originates from the photoelectrochemical oxidation of $\mathrm{Ag}$ to $\mathrm{AgO} .{ }^{22}$ The $\mathrm{CV}$ cycling is run under Raman laser irradiation without natural light during operando Raman measurements, which means that the photoelectrochemical oxidation can also be induced by Raman laser (532 nm used here).

During the anodic sweep, the intensity of the main band at $\sim 430 \mathrm{~cm}^{-1}$ is the strongest at $\sim 0.3 \mathrm{~V}$ while there is only a small amount of AgO, which should be caused by the SERS effect of the rough $\mathrm{Ag}$ surface $\mathrm{e}^{25,26}$ at a low potential range before thick $\mathrm{Ag}_{2} \mathrm{O}$ is formed. However, during the cathodic sweep from $0.8 \mathrm{~V}$ to $0.2 \mathrm{~V}$, the $\mathrm{AgO}$ signal is maintained during this whole range, implying that the reduction of AgO lasts over a wide potential range accompanied by a direct reduction of $\mathrm{AgO}$ to $\mathrm{Ag}$ at $\sim 0.2 \mathrm{~V}$. When the potential declines further, below $0.2 \mathrm{~V}$, four wide Raman bands (bands 6 to 9) emerge, which can be ascribed to the silver hydroxide $\left(\mathrm{Ag}(\mathrm{OH})_{x}{ }^{n-}\right)$ that should be formed from
$\mathrm{Ag}_{2} \mathrm{O}^{18}$ These bands are still clearly visible even when the potential is decreased to $-0.2 \mathrm{~V}$, which should be the main reason for the lower practical capacity of silver than its theoretical value.

To explore the effect of Au decoration on the faradic reactions, operando Raman analysis was also employed for the treated sample of T-Ag, as shown in Fig. 6c. It can be clearly seen that the existence of $\mathrm{AgO}$ is much shorter than that of bare $\mathrm{Ag}$, which means that the threshold potential of the photoelectrochemical oxidation of $\mathrm{Ag}$ to $\mathrm{AgO}$ increases slightly, and the full reduction of $\mathrm{AgO}$ is finished at higher potential (all of the $\mathrm{AgO}$ is reduced at the first reaction step that corresponds to the first reduction peak), indicating a much higher reversibility and reduced polarization.

Besides, the intensity change tendency is different from that of the bare $\mathrm{Ag}$ sample, which may be related to the increase in the photoelectrochemical oxidation potential (higher than the oxidation potential of $\mathrm{Ag}$ to $\mathrm{Ag}_{2} \mathrm{O}$ ). $\mathrm{Ag}_{2} \mathrm{O}$ is formed before the formation of $\mathrm{AgO}$, and hence, the SERS effect of $\mathrm{Ag}$ to $\mathrm{AgO}$ is hindered. 
Another change that is worth mentioning is that there is no obvious Raman band in the cathodic sweep range of $0.4 \mathrm{~V}$ to $-0.2 \mathrm{~V}$ after the disappearance of AgO, implying that there are no irreversible products (oxidized Ag) after the cathodic sweep. The decoration of only a little Au can largely enhance the efficiency and reversibility of the faradic reactions of $\mathrm{Ag}$ in an alkali based solution.

\section{Experimental}

\section{Sample preparation}

Silver wires (3N, Sinopharm Chemical Reagent Co., Ltd, $0.2 \mathrm{~mm}$ in diameter) with fixed length (10 $\mathrm{mm}$ exposed) were used directly after being washed with deionized (DI) water and ethyl alcohol several times and dried. The Au modification sample, T$\mathrm{Ag}$, is prepared by immersing the silver wire into a $10 \mathrm{mM}$ $\mathrm{HAuCl}_{4}$ solution for $10 \mathrm{~s}$ and then washing with DI water and ethyl alcohol.

\section{Characterization}

The morphology was examined by field emission scanning electron microscopy (FESEM, Hitachi LEO 1530) equipped with an EDS. The XRD pattern was collected through a Bruker D8 Advance X-ray diffractometer with $\mathrm{Cu} \mathrm{K} \alpha$ radiation $(l=0.15418$ $\mathrm{nm})$. Raman spectra were collected with a Horiba LabRAM HR Evolution system equipped with a semiconductor laser (with a wavelength of $532 \mathrm{~nm}$, Laser Quantum Ltd). The operando Raman signal was recorded in the time mapping mode with a cyclic voltammetry test at a scan rate of $0.625 \mathrm{mV} \mathrm{s}^{-1}$. The cell used for the operando Raman measurement is a three-electrode system with silver wire as the working electrode, Pt mesh as the counter electrode, $\mathrm{Hg} / \mathrm{HgO}(1 \mathrm{M} \mathrm{KOH})$ as the reference electrode, and a glass window through which laser can be transmitted. The electrochemical measurements, including GCD and $\mathrm{CV}$, are conducted using a CHI 660E workstation (Shanghai Chenhua Ltd, China) in a three-electrode system in a $1 \mathrm{M} \mathrm{KOH}$ aqueous electrolyte. The coulombic efficiency (CE) of an electrode is calculated based on the following equation: $\mathrm{CE}=\frac{Q_{\text {discharge }}}{Q_{\text {charge }}}$, where $Q_{\text {discharge }}$ and $Q_{\text {charge }}$ represent the charge flowing through the electrode during discharging and charging, respectively.

\section{Conclusions}

Herein, the electrochemical behavior of silver in alkaline solution is well investigated. It is found that the oxidation of $\mathrm{Ag}$ indeed undergoes two steps through two one-electron-involved processes and $\mathrm{Ag}$ can be oxidized to $\mathrm{Ag}(\mathrm{II}) \mathrm{O}$ directly at a lower potential due to the photoelectrochemical effect in the $\mathrm{CV}$ mode. Meanwhile in the GCD mode, except for the two wellaccepted reactions of $\mathrm{Ag}$ to $\mathrm{Ag}_{2} \mathrm{O}$ and $\mathrm{Ag}_{2} \mathrm{O}$ to $\mathrm{AgO}$, some $\mathrm{Ag}$ can be oxidized to AgO directly through a two-electron-transfer process in the second oxidation step, implying different activities of these reactions in the $\mathrm{CV}$ and GCD mode. Therefore, a possible approach to enhance the rate performance of the Ag- based electrode is proposed, i.e. by controlling the charge/ discharge condition to avoid the formation of high resistance $\mathrm{Ag}_{2} \mathrm{O}$.

During the cathodic CV sweep and galvanostatic discharge, reversible reactions take place. However, the CE is only $\sim 82 \%$ calculated from the $\mathrm{CV}$ curve at $5 \mathrm{mV} \mathrm{s}^{-1}$. Using operando Raman spectroscopy, it is found that the main reason for the low $\mathrm{CE}$ is the existence of irreversible reactions with the formation of $\mathrm{Ag}(\mathrm{OH})_{x}{ }^{n-}$. After the modification of $\mathrm{Au}$, the conductivity of the electrode is improved and the formation of $\mathrm{Ag}(\mathrm{OH})_{x}{ }^{n-}$ is inhibited. The coulombic efficiency is hence improved to $95 \%$ in the CV mode and $98 \%$ in the GCD mode, indicating a promising method to enhance the reversibility of Ag-based electrochemical cells.

\section{Conflicts of interest}

There are no conflicts to declare.

\section{Acknowledgements}

We gratefully acknowledge the financial support from the Fundamental Research Funds for Central Universities of SCUT, China (No. 2018ZD20), the National Science Foundation for Key Support Major Research project of China (No. 91745203) and Guangzhou Science and Technology Program (No. 20181002SF0115).

\section{References}

1 P. Wu, S. Cheng, L. Yang, Z. Lin, X. Gui, X. Ou, J. Zhou, M. Yao, M. Wang, Y. Zhu and M. Liu, ACS Appl. Mater. Interfaces, 2016, 8, 23721-23728.

2 E.-S. Lee and A. Manthiram, J. Mater. Chem. A, 2014, 2, 3932.

3 A. Dualeh, N. Tétreault, T. Moehl, P. Gao, M. K. Nazeeruddin and M. Grätzel, Adv. Funct. Mater., 2014, 24, 3250-3258.

4 M. Winter and R. J. Brodd, Chem. Rev., 2004, 104, 4245-4269.

5 Y. Wang, Y. Song and Y. Xia, Chem. Soc. Rev., 2016, 45, 59255950.

6 P. J. Hall, M. Mirzaeian, S. I. Fletcher, F. B. Sillars, A. J. R. Rennie, G. O. Shitta-Bey, G. Wilson, A. Cruden and R. Carter, Energy Environ. Sci., 2010, 3, 1238.

7 M. Zhang, A. Zhao, H. Sun, H. Guo, D. Wang, D. Li, Z. Gan and W. Tao, J. Mater. Chem., 2011, 21, 18817.

8 T. Ahmad, I. A. Wani, N. Manzoor, J. Ahmed and A. M. Asiri, Colloids Surf., B, 2013, 107, 227-234.

9 I. A. Wani, S. Khatoon, A. Ganguly, J. Ahmed, A. K. Ganguli and T. Ahmad, Mater. Res. Bull., 2010, 45, 1033-1038.

10 I. A. Wani, A. Ganguly, J. Ahmed and T. Ahmad, Mater. Lett., 2011, 65, 520-522.

11 A. M. Zamarayeva, A. M. Gaikwad, I. Deckman, M. Wang, B. Khau, D. A. Steingart and A. C. Arias, Adv. Electron. Mater., 2016, 2, 1500296.

12 C. Yan, X. Wang, M. Cui, J. Wang, W. Kang, C. Y. Foo and P. S. Lee, Adv. Energy Mater., 2014, 4, 1301396.

13 C. Li, Q. Zhang, J. Sun, T. Li, S. E, Z. Zhu, B. He, Z. Zhou, Q. Li and Y. Yao, ACS Energy Lett., 2018, 3, 2761-2768. 
14 Y. Yan, T. Wang, X. Li, H. Pang and H. Xue, Inorg. Chem. Front., 2017, 4, 33-51.

15 P. Liu, J. Liu, S. Cheng, W. Cai, F. Yu, Y. Zhang, P. Wu and M. Liu, Chem. Eng. J., 2017, 328, 1-10.

16 M. Usman, L. Pan, A. Sohail, Z. Mahmood and R. Cui, Chem. Eng. J., 2017, 311, 359-366.

17 S. S. Abd El Rehim, H. H. Hassan, M. A. M. Ibrahim and M. A. Amin, Monatsh. Chem., 1998, 129, 1103-1117.

18 N. Iwasaki, Y. Sasaki and Y. Nishina, Surf. Sci., 1988, 198, 524-540.

19 N. Y. Suzuki, P. V. B. Santiago, T. S. Galhardo, W. A. Carvalho, J. Souza-Garcia and C. A. Angelucci, J. Electroanal. Chem., 2016, 780, 391-395.

20 L. C. Nagle, A. J. Ahern and L. D. Burke, J. Solid State Electrochem., 2002, 6, 320-330.
21 I. Martina, R. Wiesinger, D. Jembrih-Simbürger and M. Schreiner, e-Preserv. Sci., 2012, 1-8.

22 R. Kotz and E. Yeager, J. Electroanal. Chem. Interfacial Electrochem., 1980, 111, 105-110.

23 P. Gao, D. Gosztola, L.-W. H. Leung and M. J. Weaver, J. Electroanal. Chem. Interfacial Electrochem., 1987, 233, 211222.

24 G. I. N. Waterhouse, G. A. Bowmaker and J. B. Metson, Phys. Chem. Chem. Phys., 2001, 3, 3838-3845.

25 J. V. Perales-Rondon, S. Hernandez, D. Martin-Yerga, P. Fanjul-Bolado, A. Heras and A. Colina, Electrochim. Acta, 2018, 282, 377-383.

26 D. Martín-Yerga, A. Pérez-Junquera, M. B. González-García, J. V. Perales-Rondon, A. Heras, A. Colina, D. HernándezSantos and P. Fanjul-Bolado, Electrochim. Acta, 2018, 264, 183-190. 